Department of Pediatrics, Harvard Medical School; and Division of General Pediatrics, Department of Pediatrics, Boston Children's Hospital, Boston, MA, USA

2 Department of Pediatrics, Harvard Medical School; and Division of Emergency Medicine, Boston Children's Hospital, Boston, MA, USA

3 Mental Health Team, Cotting School, Lexington, MA, USA

4 Department of Psychiatry, Harvard Medical School; and Brazelton Touchpoints Center, Division of Developmental Medicine, and Department of Psychiatry, Boston Children's Hospital, Boston, MA, USA

Correspondence to EA Rider elizabeth_rider@hms.harvard.edu; elizabeth.rider@childrens.harvard.edu https://orcid.org/0000-0003-3655-2205 Cite this as: BMJ 2021;374:n1730 http://dx.doi.org/10.1136/bmj.n1730 Published: 24 August 2021

PRACTICE POINTER

\title{
Mental health and wellbeing of children and adolescents during the covid-19 pandemic
}

\author{
Elizabeth A Rider, ${ }^{1}$ Eman Ansari, ${ }^{2}$ Pamela H Varrin, ${ }^{3}$ Joshua Sparrow ${ }^{4}$
}

\section{What you need to know}

- When assessing mental health and wellbeing, consider developmental stage, functional or behavioural manifestations, proximity to and severity of pandemic related hardships, and individual, family, and community strengths, supports, and protective factors

- A child or adolescent may show no observable or reported symptoms of distress, or may show them at some later time

- Primary care physicians' roles include screening, outreach, identification, referral, ongoing monitoring or surveillance, support, and coordination with specialist clinicians

- Encourage resilience in all patients, not just those presenting with mental health and wellbeing concerns

Many children and adolescents remain resilient over time and may recover rapidly after disasters such as a pandemic. However, their experiences and the burden of sustained, multiple stressors (including prior trauma, illness, attachment disruption, grief, isolation, closed borders, and home confinement) ${ }^{1-5}$ may result in a range of challenges to their mental health and wellbeing, both short and long term. ${ }^{5}$

Given that half of mental health disorders (including depression, anxiety, post-traumatic stress disorder, and others) start by age 14, and three quarters by age $24,{ }^{6}$ early recognition and treatment of the potential impacts of the covid-19 pandemic will help protect children's and adolescents' current and future mental health, development, learning, and wellbeing. ${ }^{7}$

The covid-19 pandemic, at the time of writing, affects an estimated 2.59 billion $0-19$ year olds, ${ }^{9}$ with school closures in 193 countries that have affected more than 1.59 billion. ${ }^{10}$ This article-intended for generalists and others-covers common impacts and effects of the pandemic; assessment, including recognition of symptoms suggestive of mental health disorders; and management, including referral and mitigation of the potentially adverse impacts of the covid-19 pandemic.

Wellbeing is a person's ability to recognise their own capacities, manage regular stresses of life, work productively, and contribute to their community. ${ }^{11}$ The authors advocate a trauma-informed approach, ie, remaining aware of physical and emotional traumas that children, adolescents, and families have experienced, and of the potential wide ranging repercussions of these traumas. ${ }^{12-16}$ This includes understanding the severity and nature of events and their impact.

\section{What does the evidence show?}

At the time of writing, most research on covid-19 has focused on adults. ${ }^{17^{-20}}$ Research on the mental health effects of the pandemic on children, adolescents, and their families is limited and in some instances contradictory..$^{21-24}$ Many of the studies use life satisfaction and wellbeing assessments that are, in general, not intended to detect or predict diagnosable mental health disorders.

Most evidence specific to covid-19 depends on data that are limited because of self-selected/self-reporting participants, smaller sample sizes, virtual-only data collection, heterogeneous samples limiting data aggregation, and short term only outcomes.

The strongest evidence is not about the mental health effects of covid-19-that will emerge over the years to come-but for previously well established mental health disorders in children, for example, depression, anxiety, post-traumatic stress disorder, and for risk and protective factors for these disorders.

While longer term outcomes specific to covid-19 remain unknown, guidance can be extrapolated from previous large scale disasters, for example, the Indian Ocean earthquake/tsunami of 2004, the Nepal earthquakes in 2015, the Deepwater Horizon Gulf of Mexico oil spill in 2010, Hurricane Katrina in 2005, and disease outbreaks including the $\mathrm{H}_{1} \mathrm{~N}_{1}$ influenza pandemic of 2009 and the Ebola epidemic of 2014. . $25-30^{25}$

The advice in this article is based on a comprehensive evidence based literature search and analysis; guidelines and policy papers; consensus based guidance from national and international organisations; input from patients and parents; input from clinical, academic, and patient reviewers; and our own clinical experience.

\section{Varying evidence}

Some data are contradictory, at times reflecting divergent effects of the pandemic on younger children and adolescents, individual differences and contexts, and the impact of social determinants of health.

For example

- Data from studies in multiple countries-including a longitudinal probability study that assessed youth in 2017 and $2020^{31}$; a retrospective comparison of emergency department suicide risk screens comparing results from January-July 2019 with January-July $2020^{32}$; a cross-sectional study of emergency department patients between January 2018 and January 2021 23 ; and a study of 
suspected suicide attempts between March 2020 and May 2021 compared with the same periods in $2019^{34}$-all suggest increased frequency of mental health disruption and mental health disorders during the pandemic, and that prior mental health disorders can increase the risk of pandemic related or induced mental health trauma. ${ }^{22233135-50}$ However, a proportion of these data also shows that some children with prior and/or ongoing mental health disorders have had reduced symptoms during the pandemic. $223136394^{-50}$ This may be because of a pause on the demands of in-person schooling (peer interactions, sensory over-stimulation, etc) ${ }^{4751}$ as well as increased access to supportive parents who are forced to stay at home.

- Systematic and narrative reviews and technical reports show screen time can support online learning and online connection with family, friends, ${ }^{52}$ and services, ${ }^{35}$ but lack of access to the internet or devices widens disparities. ${ }^{2353}$ Other technical reports, evidence reviews, systematic evidence mapping, and international investigations (Europol) report cyberbullying, cybercrime, privacy issues, $3553-56$ and screen fatigue. ${ }^{57}$

\section{How do you assess mental health and wellbeing?}

The following information is relevant to most consultations; ie, for children or adolescents attending expressly for mental health concerns, as well as those presenting with other symptoms. All children and families have experienced the pandemic in some way.

Start with a brief history of pre-pandemic physical and mental health and school functioning, and compare pandemic related findings with this baseline.

Include an interview with the child or adolescent, as well as the parent or adult caregiver whenever possible (see box 1 for prompts). $58-60$

Box 1: Suggested prompts for children or adolescents, according to developmental stage

Young children (ages 3-5)

- Did you hear about the virus that has been making some people sick? If the child does not respond or answers no, stop here, and ask parents

- Did you know about anyone who got sick? What happened to them?

- Do you think anyone else might get sick?

- Did anyone in your family have to stay at home while this virus was making people sick? Who? What did you think about that?

Older children (ages 6-11) and adolescents

- Did you know about anyone who got sick from the virus? What happened to them?

- Do you think anyone else might get sick?

- Did you hear about the vaccines? What do you think about that?
- Did you or anyone in your family have to stay at home during this pandemic?

- What was that like?

- Did anyone in your family lose their job or have more trouble making money?

- Did you get in touch with your friends when everyone had to stay at home? How did that go?

- What was the worst part of this whole thing for you?

- Were there any things you liked about it?

- What do you think is going to happen after this pandemic?

Keeping in mind developmental stages, ${ }^{5859}$ ask children about their understanding of the pandemic: Why did it happen? How have they responded? How has it affected them? What are their fears and worries? What helps them to feel safe? Validate their descriptions of any negative effects on their wellbeing and on friends, families, and activities.

What are their immediate needs (eg, food, shelter, safety, adult caregiver availability)? What is the current family constellation? What is the parent/family experience of and response to the pandemic (eg, job loss, new or exacerbated parental mental health challenges)? What supports currently exist (eg, family or social network; financial or material resources; access to healthcare and social supports; longstanding effective mechanisms for coping with adversity; spirituality/religious community)?

\section{Consider what factors might be affecting mental health and wellbeing}

Has the child or their family been exposed previously to trauma, separation, or loss, including adverse childhood experiences? ${ }^{72} 61$ Is there a history of mental health disorder? Prior school performance challenges? What coping capacities has the child previously used? Is the child readily able to accept adult help?

Inquire about experiences related to covid-19, eg, deaths, serious illness, separations, hunger, safety, financial hardships, parental unemployment, food and housing security, school disruption, disrupted peer interactions, disrupted physical and extracurricular activities.

Grief after a death in the family is expected. However, grief complicated by disruption of traditional grieving rituals, multiple deaths, limited or no access to social or professional support, can increase the risk of mental health disorders. Inquire about parents' grief or depressive symptoms (these may impact the child/adolescent).

Factors that can contribute to child or adolescent vulnerability during the covid-19 pandemic are summarised in fig 1 and table 1. 

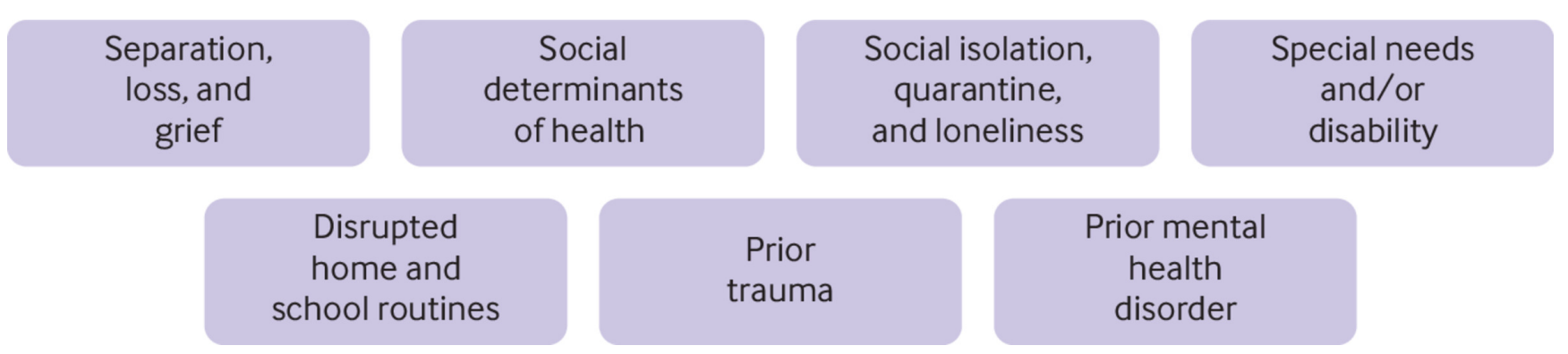

Fig 1 | Factors contributing to child and adolescent vulnerability during the covid-19 pandemic 
Table 1| Examples of factors contributing to child and adolescent vulnerability during the pandemic

Factor

Separation, loss, and grief

Social isolation, quarantine, and loneliness

Social determinants of health

\section{Examples}

- Separation from primary caregivers or other family owing to illness, quarantine/lockdown and caregiver death can cause anxiety, sadness, or fear of their own or another caregiver's death.23 62.64 This is compounded when caregivers are frontline or essential workers at increased risk of contracting covid-1961

- Grieving processes can be disrupted when traditional rituals such as funerals and family gatherings are impeded

- Caregiver or family financial hardship and food or housing insecurity ${ }^{65}-67$; inadequate internet/device access for learning ${ }^{68}$; and poor access to green space ${ }^{69}$ can affect wellbeing - In communities with higher rates of severe illness or death, ${ }^{70}{ }_{-} 22$ the chance of experiencing multiple losses in short order is greater:

- $20 \%$ of Black children in the US (versus $14 \%$ of the total population) have experienced death of a caregiver from covid-19 73

- Many Native American sovereign nations and communities have experienced high death rates owing to chronically inadequate healthcare resources, while some remote communities have successfully reduced infection rates by mandating masks, providing rapid testing and sufficient personal protective equipment (PPE), and shielding older people ${ }^{/ 4}$

- Globally, some studies of indigenous peoples suggest lower covid-19 fatality rates, possibly because of isolation. Inadequate access to covid-19 testing and low quality data hinder accurate conclusions ${ }^{7576}$

- Facility closure (schools, community centres. spiritual institutions, food programmes) has caused loss of connection with teachers, friends, peers; lack of access to usual support systems $^{377778}$; reduced physical activity ${ }^{35}$; loss of instructional time ${ }^{10}$; and increased screen time from virtual learning/socialising/gaming/digital media use

- These factors potentially lead to increased risk of depression and anxiety 4079 ; emotional dysregulation, hyperactivity/inattention and conduct problems in children aged 4-1080; screen fatigue $^{57}$; exposure to cybercrime 535681 ; and post-traumatic stress reactions ${ }^{82}$

- Additional parenting demands/loss of previous childcare place some children at increased risk for maltreatment, but key reporters and observers of maltreatment (ie, school personnel) are not physically available during school closures 83

-While important in mitigating infection, masks, physical distancing, and lockdowns can potentially affect peer relationships, communication, and social-emotional development, particularly of children under 4 and developmentally vulnerable children 284

- Increased exposure to social media and news reporting has heightened anxiety and stress, worsening or triggering behavioural health conditions, ${ }^{83}$ and is associated with disruption to sleep and circadian rhythm, ${ }^{35}$ and increased vulnerability to bullying and abuse. ${ }^{23}$ However, social media use also can help cope with stress and social isolation, increasing social connection, self-expression, and access to information, especially for adolescents. ${ }^{35} 54$

- Thirty per cent of isolated or quarantined children and adolescents during the SARS, Ebola, and the 2009 and 2010 H1N1 influenza pandemics developed PTSD, a statistically significant higher number than those not isolated. ${ }^{85}$ Prevalence was higher with $>10$ days of quarantine ${ }^{86}$

Physical, intellectual, and/or learning disabilities

- Access to in-person evaluations, physical and occupational therapy, speech and language therapy, and medication/nutrition support previously provided in the school setting may be lost 83

- Parents may lose contact with supportive adults and respite options

- School closures reduce opportunities for social skill development

- Online learning is more difficult for students with executive functioning skills challenges such as difficulty paying attention and focusing, and limited impulse control, perseverance, and frustration tolerance

Disrupted home and school routines - Can increase child and parental stress, increase screen time, reduce physical activity, ${ }^{35} 53$ and increase risk of domestic violence exposure or abuse 238788

Prior trauma
- Domestic violence, child abuse/maltreatment, and adverse childhood events, ${ }^{712} 61$ are risk factors for pandemic-related trauma and exacerbated pandemic effects

Prior mental health disorder

- As well as increasing the risk for pandemic related or induced trauma leading to functional disruption, 12138990 the pandemic has also interfered with access to ongoing mental health treatment previously available at schools ( $35 \%$ of US youth receiving mental health services access these services exclusively in school) ${ }^{78}$

\section{Ask about the effects of covid-19 related events or experiences}

What have been the physical and emotional effects of the child's or adolescent's experiences of covid-19? Limited comprehension of pandemic related changes in routines and circumstances, frustration, and distress are often expressed through behaviour and can affect functioning in developmental domains such as sleeping, feeding or eating, behavioural control or regulation, mood, cognitive capacities (eg, attention, concentration, school performance), and family and peer relationships.

Common behavioural and functional responses to extraordinary circumstances, like the covid-19 pandemic, are summarised in table 2. 
Table 2 | Common child and adolescent behavioural and functional responses to adversities, by developmental stage 585991

\begin{tabular}{|c|c|}
\hline Stage & Potential responses of child/adolescent* \\
\hline $\begin{array}{l}\text { Infants and toddlers } \\
(0-3 \text { years })\end{array}$ & $\begin{array}{l}\text { - Aware of parents'/caregivers' worry } \\
\text { - Fear, worry, sadness, in response to parents'/caregivers' fears, worries, sadness } \\
\text { - Regression from previously achieved milestones-eg, toilet training } \\
\text { - Increased crying, clinging } \\
\text { - Sleep disturbances such as refusal to separate at bedtime and difficulty falling asleep } \\
\text { - Increased testing of limits (toddlers) }\end{array}$ \\
\hline $\begin{array}{l}\text { Preschool children } \\
\text { (3-5 years) }\end{array}$ & $\begin{array}{l}\text { - Primary concerns are separation from and safety of family members } \\
\text { - Increased generalised fears and fears of separation, "germs", contamination, etc. } \\
\text { - Regression in emotional and behavioural control, eg, increased irritability, crying, clinging, } \\
\text { resistance to separating at bedtime, bed wetting, other medically unexplainable physical } \\
\text { symptoms such as stomach aches and headaches } \\
\text { - Fear of and confusion about television images, including those of protective gear, masks, } \\
\text { bodies, etc } \\
\text { - Re-enactment, sense-making and mastery through play and drawings } \\
\text { - Belief that they or their real or imagined misbehaviours are the cause of illness or traumatic } \\
\text { events, and resulting guilty feelings; magical thinking, eg, "If I'm really good, Daddy won't die" }\end{array}$ \\
\hline $\begin{array}{l}\text { School aged children } \\
\text { (6-12 years) }\end{array}$ & $\begin{array}{l}\text { - Work through their feelings, thoughts, misunderstandings in their play and may replay images } \\
\text { they have seen } \\
\text { - Fear of and confusion about television images, including those of protective gear, masks, } \\
\text { bodies, etc. Concern about their safety } \\
\text { - Ask many questions } \\
\text { - More irritable than usual; may be detached and withdrawn } \\
\text { - Anxiety, fearfulness, eg, non-specific, or of germs, illness, death, the unknown } \\
\text { - Medically unexplainable stomach aches, headaches, sleep disruption, appetite changes } \\
\text { - Decreased academic performance, disruptive behaviours } \\
\text { - Able to understand the cause of illness as external to themselves (eg, "you get a cold from } \\
\text { not wearing a coat"), rather than as their own fault }\end{array}$ \\
\hline $\begin{array}{l}\text { Adolescents } \\
\text { (13-17 years) }\end{array}$ & $\begin{array}{l}\text { - Able to understand many of the implications } \\
\text { - Legitimate fears about the future (eg, economic repercussions, long term health issues) } \\
\text { - Varied responses: worry, fear, sadness, anger, disillusionment, avoidance, withdrawal } \\
\text { - Anxiety, eg, "Will I be okay?", "Will my parents be OK?", "Will I ever see my friends again?", } \\
\text { "Will my school ever open again?", "What will my life be like?" } \\
\text { - Depressive symptoms such as loss of hope and future orientation: "Nothing will ever get } \\
\text { better." } \\
\text { - Reduced life satisfaction93 } \\
\text { - Fearfulness, eg, non-specific, or of germs, illness, death, the unknown } \\
\text { - Sleep disturbances related to anxiety, depression, fearfulness, decreased physical activities, } \\
\text { and disruption of routines and schedules } 94 \\
\text { - Decreased interest in social activities, peers, school } \\
\text { - Increased risk taking: failing to wear mask or social distance, potential alcohol or other substance } \\
\text { abuse, unsafe sexual behaviours } \\
\text { - Difficulty concentrating, academic difficulties } \\
\text { - Expression of concerns about trust in public institutions, justice, power, and control } \\
\text { - Desire to discuss the policy issues involved } \\
\text { - Able to integrate multiple factors in understanding illness and to imagine alternative possibilities }\end{array}$ \\
\hline
\end{tabular}

* None to all responses might be present. These responses may present on a continuum from mildly distressing to severely disruptive.

Observe for and inquire about the severity and duration of distress associated with these functioning domains. These will depend, in part, on the proximity to pandemic related traumatic events and hardships, and to the severity of these events and hardships (eg, separations from/losses of primary caregivers), ${ }^{919596}$ as well as on developmental stage. The longer distress persists over time, the more likely it is to disrupt peer and family relationships and school performance.

\section{Look for responses that might indicate a mental health disorder}

The behavioural responses listed in table 2 fall on a continuum from developmentally expected and mildly distressing to severely disruptive to the child/adolescent and/or others. Severe disruption of one or more functional areas is more likely to indicate a mental health disorder than mild distress.

The length of time a behaviour has persisted might also indicate the presence of a mental health disorder-the DSM V, for example, specifies minimum duration of symptoms qualifying for diagnoses of disorders such as depressive and anxiety disorders, and trauma reactions. ${ }^{97}$ Generally, consider diagnosing a mental health disorder when responses occur for long enough to affect functioning.

\section{Assessing distress}

Distress associated with some areas of functioning may be subjective and may not be reported. A toddler, for example, may express distress through facial or verbal expressions of worry. More severe disruption in functioning may include relentless clinging to the caregiver, refusing to let the caregiver leave, loss of usual play behaviours when the caregiver is not present, etc.

Mildly distressing fears could be expressed by articulating fearfulness; whereas disruptive functioning might include panic attacks, or extreme avoidance of the sources of fear, eg, refusal to leave home when necessary.

Mild sleep disturbance in any age group may include occasionally taking longer to fall asleep and/or waking feeling fatigued. 
Disruption in sleep functioning, however, would include prolonged difficulty falling asleep on most nights, resulting in persistent daytime fatigue and related irritability.

Children/adolescents may also present to primary care or to the emergency department with medically unexplainable physical symptoms (eg, abdominal pain, headache) that are a manifestation of their distress, with or without clear signs or symptoms that are more commonly associated with mental health disorders (eg, depressed mood, loss of interest and pleasure in usual activities, low energy, anxiety, sleep disturbances, withdrawal/social isolation, suicidal ideation).

Severity of distress can also be determined by pervasiveness of symptoms across developmental domains (eg, more than one of the functional areas listed above), or across more than one self-regulatory capacity (eg, attention, frustration, tolerance, perseverance, impulse control, expressing emotions), or across more than one formal or informal learning capacity (eg, curiosity, exploration, motivation for learning, constructive risk taking in service of learning).

Many children and adolescents experiencing distress, whether reported or observable or not, may not develop symptoms of a mental health disorder, or may only develop them at some later time. 9899

\section{Screening}

Simple, brief mental health screening (as recommended at regular intervals from infancy through adolescence by the American Academy of Pediatrics), including programmes that consider the whole family, may be used to help assess for emotional symptoms, behavioural functioning symptoms, and psychosocial symptoms ${ }^{100101}$ (box 2).

\section{Box 2: Screening tools}

- Mental health screening can be used to detect emotional and behavioural functioning/psychosocial symptoms, and can help identify when referral for evaluation and treatment or other supports are needed ${ }^{100}$

- Since 2016, the US Preventive Services Task Force has recommended screening for major depressive disorder for all adolescents aged $12-18,{ }^{102}$ and notes that the Patient Health Questionnaire for Adolescents (PHQ-A) and the primary care version of the Beck Depression Inventory are the screening tools used most often

- The National Institute of Mental Health recommends suicide screening for all children ages 8 and above presenting to the emergency department, outpatient, and inpatient settings using the four-item brief screening questionnaire ASQ (Ask Suicide-screening Questions) ${ }^{103104}$

- Recent studies comparing the PHQ-9A and the ASQ in 803 adolescents aged 12 and older in June 2019 to October $2020^{105}$ and 600 medical inpatients aged $10-21^{106}$ found the ASQ suicide risk screening identified patients not identified by other depression screening

- A list of paediatric mental health screening tools, including global tools, can be downloaded from the American Academy of Pediatrics' website. ${ }^{107}$ These and other tools ${ }^{100} 108$ can help assess and identify children and adolescents who require referral for formal psychiatric evaluation $^{109-111}$

Box 3 includes signs that could suggest a mental health disorder.
Box 3: Behavioural responses and signs that could indicate a mental health disorder, and when to refer for specialist assessment

Consider referral for specialty care when these symptoms are present (as soon as possible, according to local protocol) ${ }^{5} 8298$ :

- Anxiety and/or depressive symptoms

- Increased arousal, mood changes, irritability, withdrawal, emotional numbing, being overwhelmed

- Physical symptoms such as fatigue, headaches, or stomach aches that cannot be medically explained

- Disordered eating habits

- Sleep disturbances, including unrestful sleep, trouble falling asleep, middle of the night waking

- Traumatic grief

- Symptoms of post-traumatic stress disorder-eg, that disrupt functioning and/or can create risk of harm to self or others

Nightmares

Re-experiencing the event/disaster

Intrusive thoughts-eg, that interfere with focus, concentration, attention

- Increased arousal-eg, that may lead to aggressive behaviour

Hypervigilance-eg, that may lead to aggressive behaviour

Avoidance of activities, experiences, or places associated with the event or disaster and/or more general withdrawal

Emotional dysregulation or dissociation

These symptoms require referral for emergency/immediate mental health evaluation ${ }^{98}$ :

- Suicide attempt; suicidal ideation, intent or plan

- First known self-cutting; repeat self-cutting if patient has no existing mental health clinician

- Intense fear, anxiety, helplessness, panic or horror, especially if these disrupt basic areas of functioning such as sleep, eating, family and peer interactions, academic performance

- Presence of dissociative symptoms such as detachment, depersonalisation, derealisation, eg, child may appear distant, aloof, confused, daydreaming

- Extreme confusion or inability to make simple decisions

- Uncontrollable and intense grief

- Intrusive thoughts or severe cognitive impairment

- Debilitating physical complaints suggestive of bodily symptoms in the absence of medical explanation

\section{How can you manage children's and adolescents' mental health and wellbeing?}

Trauma informed management in primary care ${ }^{12}$ can help patients and families to access community supports, and, when indicated, to access mental health treatment and specialty care. In the face of the covid-19 pandemic, all children/adolescents/parents may benefit from resources and support to restore their resilience ("the ability to maintain or regain mental wellbeing, despite adversity" $\left.{ }^{112}\right)$. A smaller group requires additional support and guidance; and an even smaller number need specialist treatment.

We have adapted the stepwise, trauma informed management approach that is recommended by the Center for Pediatric Traumatic Stress ${ }^{113114}$ and others ${ }^{115} 116$ to be applicable during the covid-19 pandemic (fig 2). 


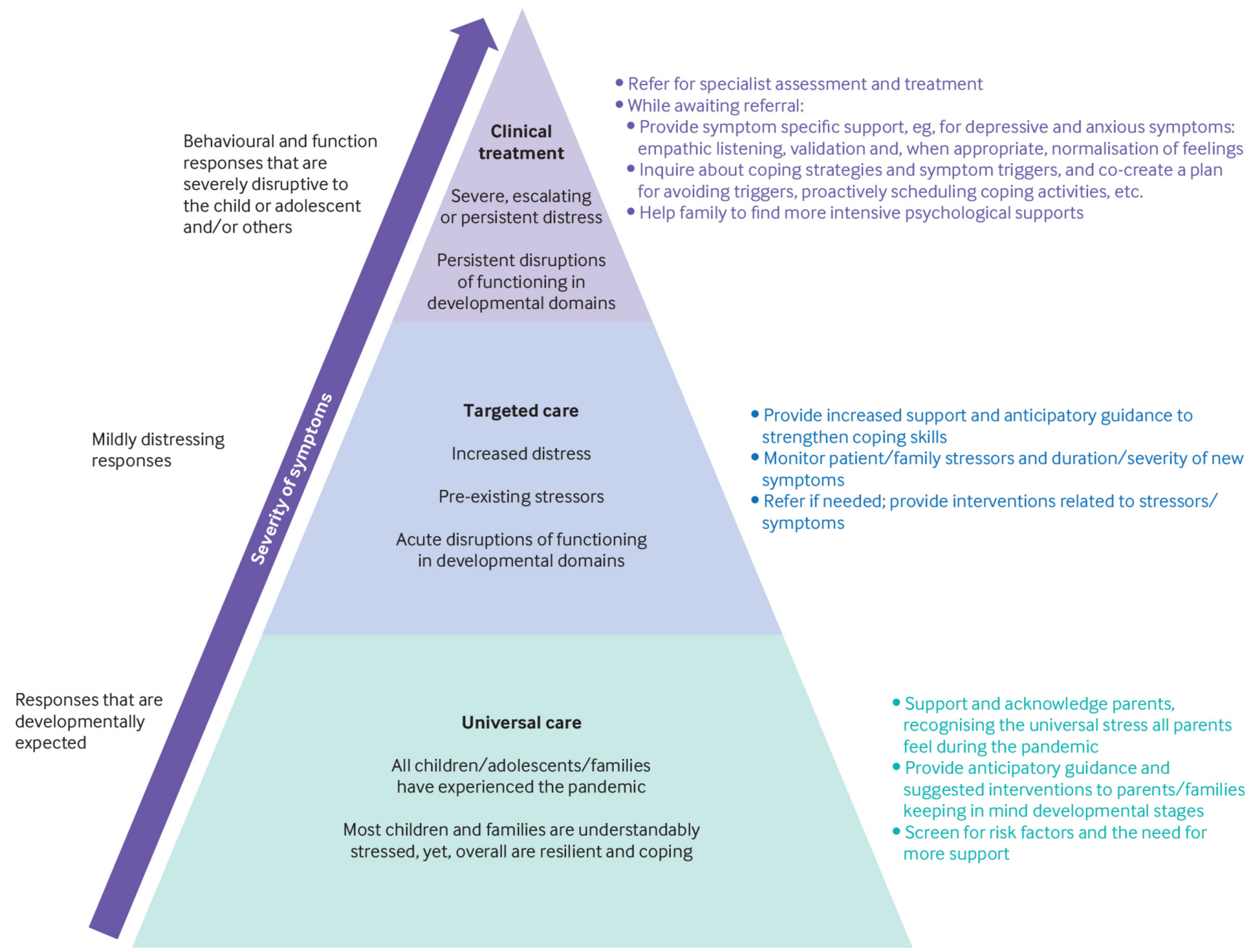

Fig 2 | A stepwise model for management,* adapted from the Pediatric Preventative Psychosocial Health Model ${ }^{113} 114$ and the Multi-tiered System of Support model. ${ }^{115} 116$ See box 3 for symptoms requiring emergency/immediate mental health intervention

\section{Support parents and caregivers and encourage consistency and sensitivity}

Strong family relationships and positive interactions (in person, by phone, or online) are protective factors that can bolster resilience. Appreciate and reinforce parents' efforts to be present and empathetic, 59 to focus on the present, help their children to grow and continue learning, and model positive coping and stress reduction strategies ${ }^{63}-\mathrm{eg}$, physical activity, regular use of safe green spaces, and pursuing social connections and routines (while adhering to physical distancing or mask use). These efforts can help reduce effects of the pandemic in children and adolescents such as hypervigilance, lack of trust in adults, self-regulation issues, and inappropriate social interactions, and can provide protection from developing a mental health disorder. ${ }^{115}$

Encourage open, age appropriate parent-child-family discussion about coping with the pandemic, including addressing concerns. ${ }^{3963}$ Cross sectional surveys and narrative reviews emphasise the importance of communication in mitigating symptoms of anxiety, depression, and stress. 3964

Counsel parents in talking about illness or death-how to provide simple, clear information about family health problems, in calm and neutral tones, while avoiding minimisation of any serious health threats; and realistic reassurance (eg, "Your parents are doing everything they can to make sure you and they stay healthy"). Avoid false promises that may not be possible to keep and might later damage the child's ability to trust (eg, “Don't worry, you will be fine”). Box 4 offers advice about children or adolescents who have experienced the death of one or more caregivers or family members.

\section{Box 4: Death of a family member}

In the US, alone, at the time of writing, approximately 37300 to 43000 children and adolescents have experienced a parent's death from covid-19. ${ }^{73}$ Globally, more than 1.5 million children under age 18 lost a parent, custodial grandparent, or secondary caregiver in the first 14 months of the pandemic. ${ }^{117}$ Here is some advice, based on clinical experience, for working with children or adolescents who have experienced the death of a caregiver or family member:

- Ask adult caregivers and the child about family members, friends, teachers, and others who are providing emotional and material support and whether the child experiences these as helpful, comforting, and trustworthy

- Consider referring for mental health evaluation if family and/or social supports are lacking

- Confer with adult caregivers about, and monitor for, depression, behavioural changes, or disruptions in development and learning 
during the first six months, at regular intervals over the following 12-18 months, and as anniversaries of family members' deaths approach

- Assess for suicidality, for example, by asking questions about the child's hope for the future. Refer for emergency mental health evaluation and treatment if any concerning findings are elicited

See the American Academy of Pediatrics' report on Supporting the Grieving Child and Family for additional advice ${ }^{3}$

Support parents, ${ }^{118}$ and acknowledge the understandable pandemic related stresses affecting all parents, as well as those specific to their situation. Offer information about referrals and available resources $^{101}$ - psychological, physical, social, spiritual, formal and informal-that support wellbeing. Acknowledge the variable capacity of communities and governments to make needed resources available, and empathise with the hardships that result from inadequate resources. ${ }^{2840778995112}$ Work with teachers and schools, public health professionals, and other community bodies to secure access to food, housing, physical and mental health services, and reliable childcare.

Encourage parental self-care, including creative outlets, supportive social interactions (with appropriate safety precautions), healthy nutrition, physical activities and exercise. ${ }^{94119}$ Consider discussion of mindfulness, spiritual practices, and cultural traditions for sense making and healing. ${ }^{119}$

Provide anticipatory guidance and suggested interventions to parents and caregivers, keeping in mind developmental stages (table 3).

\section{Table 3 | Practical guidance to share with parents and caregivers by developmental stage*}

\begin{tabular}{|c|c|}
\hline Stage & Suggested interventions and guidance \\
\hline $\begin{array}{l}\text { Infants and } \\
\text { toddlers } \\
\text { ( } 0-3 \text { years) }\end{array}$ & $\begin{array}{l}\text { - Identify supports and activities that help adult caregivers remain calm, patient, and reassuring } \\
\text { with infants and toddlers } \\
\text { - Attempt, whenever possible, to preserve normal routines } \\
\text { - Shield toddlers from media coverage } \\
\text { - "Special time" with parent/caregiver when possible }\end{array}$ \\
\hline
\end{tabular}

Preschool children

(3-5 years)

- Provide reassurance about the child's and family's safety and what is being done to prevent future infection (eg, handwashing, staying home, mask wearing, vaccination)

- Answer questions simply and watch the child's face to know when the child has heard enough

- Label and validate the child's feelings

- Attempt to preserve, as much as possible, normal routines

- Limit television/media exposure; young children do not understand the images they see and may be frightened by them

- Ensure that the child knows parents' and family members' whereabouts and schedules

- Develop opportunities for the child to play and relax; engage with the child in interactive play

- Offer suggestions for positive resolution of play scenarios if children repeatedly persevere with one scenario (children work through issues through play)

School aged children

(6-12 years)
- Answer child's questions directly and honestly; let child know you are available to talk further

- Provide information in an open, age-appropriate, reassuring manner

- Be open to questions: "Tell me more about that"

- Label and validate feelings: "Yes, it is scary, and this is what we are doing to do to stay healthy"

- Ask their opinions

- Keep usual routines where possible

- Focus on positive behaviour, rather than negative behaviour

- Minimise television viewing; if they do hear news reports, be present and clarify what they see or hear

- Encourage participation in family or other efforts to help as appropriate

- Offer suggestions for positive resolution of play scenarios if children repeatedly persevere with one scenario (children work through issues through play)

- Show respect for the adolescent's feelings

- Discuss the adolescent's opinions, feelings, and different ways to cope

- Discuss causes and effects of the covid-19 pandemic

- Listen to and talk about what adolescents see on social media and hear from their friends

- Be present if they watch television; discuss and provide perspective

- Check in regularly

- Address risk taking behaviours clearly and directly

- Share and talk about reactions to covid-19 related disruptions (eg, virtual graduation, cancellation of prom, etc)

- Normalise experiences: "You're not alone; everyone is struggling"

- Encourage adolescent to connect with their friends-in person if restrictions are lifted; or virtually, by phone, or taking the advised safety precautions (eg, outdoors, masks, no physical contact, etc)

- Share your own feelings and coping mechanisms (be a role model)

- Adolescents may want to participate in efforts to help. Help them to engage in community or other projects as appropriate

\footnotetext{
* Adapted from references55859 For all interventions, take into consideration the context in which they occur as well as cultural differences, beliefs, and practices.
} 


\section{Monitor the duration and severity of new symptoms}

Many children and adolescents need only family, primary care, and/or community supports to cope and recover from pandemic induced distress, but some will develop behavioural or functional manifestations that might indicate ongoing distress.

Be aware of the difference between responses that are mild on the severity continuum and symptoms that could indicate a mental health disorder (box 3).

A minority of children and adolescents (ie, those with persistent, severe, or escalating distress and/or severe, prolonged disruption of functioning) need evaluation and treatment by a mental health specialist and more intensive psychosocial support (box 3, fig 2).

\section{When to refer to specialist services}

In accordance with local protocol and resources, refer as soon as possible after recognising symptoms that may suggest a mental health disorder-anxiety, separation anxiety (that may manifest as school refusal with return to school after long lockdowns), depression, and post-traumatic stress disorder are among the most frequently identified disorders during the covid-19 pandemic. 35

Immediate specialist assessment is required for any suicide attempt, ideation, intent, or plan; first known or repeat self-cutting; intense fear, anxiety, helplessness, panic, or horror, especially if basic functioning is disrupted; dissociative symptoms; extreme confusion; uncontrollable or intense grief; intrusive thoughts; severe cognitive impairment; and debilitating physical complaints suggestive of bodily symptoms in the absence of medical explanation. See box 3 for more detailed referral criteria.

The American Academy of Pediatrics, ${ }^{120}$ Philippine Pediatric Society, ${ }^{121}$ American Academy of Child and Adolescent Psychiatry, ${ }^{122}$ and the American Psychiatric Association ${ }^{123}$ recommend routine and crisis telemedicine and teleconsultation, and the International Paediatric Association ${ }^{124}$ currently recommends these during the pandemic. Telepsychiatry is widely used and effective ${ }^{125}$; however, access is inequitable, ${ }^{120}{ }^{124-126}$ and it may not be effective for many young children who require interactive play therapies.

\section{Offer ongoing mental health support for all children/adolescents}

Follow child or adolescent mental health closely in primary care, in conjunction with parents, teachers and schools, public health professionals, and other community resources. Trauma,

complications of grief, anniversaries of separations, deaths, and changes in the community can continue to affect some children and families for months, or even years..$^{98}$

\section{Might children and adolescents living through this pandemic present with mental health disorders in the future?}

Data from previous pandemics and epidemics suggest that observable symptoms of mental health disorders may not show until well after the traumatic event ${ }^{98}$; and that post-traumatic stress, detachment, insomnia, and anger can be experienced up to three years after being quarantined. ${ }^{86}$ However, longitudinal studies after disasters in the US (Hurricanes Katrina and Gustav; Gulf oil spill) suggest an overall decrease in trauma distress symptoms over time, especially in younger children..$^{29}{ }^{127} \mathrm{~A}$ follow-up study after the Boulder Creek Dam collapse also found that PTSD symptoms in children and adolescents decreased from $32 \%$ at two years after the disaster to $7 \%$ after 17 years. ${ }^{128}$

\section{Education into practice}

- What covid-19 related mental health challenges do children and adolescents in your community face?

- How do you distinguish between mild responses and symptoms that might indicate a mental health disorder at different developmental stages?

- What community resources do you have that may be helpful for children and their families, eg, teachers, in-school services (where schools are open), early intervention programmes, and other community programmes?

\section{How patients were involved in the creation of this article}

Our parent coauthor (PV) has lived experience as the parent of a young adult with special healthcare needs. She teaches as "family faculty" (representing the voice of the parent/family) in workshops for healthcare professionals and is a clinical psychologist and family support coordinator at a school for students with special needs. She contributed to the material on school closings and reopening, and children with special needs.

Three parent contributors, one an autism/special needs teacher, reviewed a draft of the manuscript. Their insights are incorporated into the sections on school closures, children with disability and special needs, and green space activity. From patient reviewers, we added two new review studies, additional critical analyses of impacts, and additional suggested resources for parents.

Finally, four children, ages 6-18, were asked about their experiences with lockdown. They shared their worries about parents who are healthcare workers; finding supports (parents, siblings, friends, teachers); and getting outside. We incorporated these in tables 1,2 , and 3.

\section{Search strategy}

Our literature searches in PubMed and Web of Science began with the terms: "COVID-19" OR “Coronavirus" AND "children" OR "pediatric" OR "adolescent” OR "teen" OR "parent” OR “caregiver" AND “mental health" OR "psychological” OR "emotion" OR "psychiatry". We used multiple combinations of keywords: pandemic, disasters, quarantine, lockdown, social isolation, physical/social distancing, school closures, school re-openings, anxiety, depression, PTSD, primary care, stress, child mental health, child development, behaviour, trauma-informed care, social determinants of health, families, telehealth, and others. We also searched for information from past epidemics/pandemics (eg, SARS, H1N1, MERS). We reviewed systematic, narrative, and rapid reviews and meta-analyses. Additional literature was found in the references of identified articles, and citation chaining of relevant articles in Google Scholar. The initial search occurred in May 2020 with frequently updated searches until July 2021. Given the importance of international experiences and findings in this rapidly developing pandemic, we included studies related to covid-19 and reports from various countries including Australia, Bangladesh, Brazil, Canada, China, Egypt, France, Germany, India, Italy, Nepal, Norway, Philippines, South Korea, Spain, UK, US, and others. Additional sources used for this paper are listed in the box "How this article was made."

\section{How this article was made}

The authors of this article represent fields of primary care paediatrics, child psychiatry, paediatric emergency medicine and critical care, clinical psychology, and clinical social work.

Very little research evidence exists regarding mental health issues and wellbeing in children and adolescents during pandemics, including covid-19, SARS, and MERS. Although conclusive, evidence based guidelines for assessment and management of covid-19 related mental health effects in children and adolescents do not yet exist, we base our recommendations on

- Evidence based literature including searches in PubMed and Web of Science 
- Guidelines, policy, and position papers from other pandemics and natural disasters from the American Academy of Pediatrics, National Institute for Health and Care Excellence, and the International Paediatric Association

- Consensus based guidance from national and international health organisations, eg, World Health Organization, United Nations, Centers for Disease Control and Prevention, Unesco, Organisation for Economic Cooperation and Development

- Limited early evidence on mental health related effects of covid-19 on children and adolescents

- Well designed, longitudinal survey studies following parents and youth in the UK and US

- Our own clinical experience

\section{Potential areas for further research}

- School closure impacts-research findings are varied and conflicting. ${ }^{22}$ Challenges for future research will include unlinking the effects of school closures from other pandemic related life changes, and identifying individual, family, and community factors contributing to differential outcomes

- Long term impacts of the pandemic on children's and adolescents' mental health and wellbeing, as well as the effectiveness of interventions administered during or after the pandemic for pandemic related effects. Challenges will include causal attribution of pandemic impacts versus non-pandemic related factors, especially given child and adolescent mental health declines observed prior to the pandemic

- Outcomes and mitigating factors for children and adolescents who have experienced loss of a parent or carer because of covid-19

- Community level and cultural factors affecting the pandemic's effects on child or adolescent mental health

- Possible positive effects on child or adolescent coping, resilience, wellbeing, and individual, family, community, and cultural factors contributing to positive effects

\section{Resources for physicians and other professionals}

\section{General covid-19 resources}

- American Psychological Association. APA covid-19 information and resources. 2021. https://www.apa.org/topics/covid-19/index

- Boast A, Munro A, Goldstein H. An evidence summary of paediatric covid-19 literature. Don't forget the bubbles. UK and Australia. 2021. https://doi.org/10.31440/DFTB.24063

- Kassam-Adams N, Schneider S, Kazak AE, Center for Pediatric Traumatic Stress (CPTS). Addressing the psychological and emotional impact of the covid-19 pandemic for children, families, and healthcare staff. Health care toolbox. 2021. https://www. healthcaretoolbox.org/tools-and-resources/Covid19.html

- American Academy of Child and Adolescent Psychiatry. Coronavirus/covid-19 resource library. 2021. https://www.aacap.org/coronavirus\#clinicians

- American Academy of Pediatrics. Mental health promotion and problem prevention: pediatric mental health minute series. 2020. https://services.aap.org/en/patient-care/mental-healthminute/mental-health-promotion-and-problem-prevention/

- Schonfeld DJ, Demaria T, Committee on Psychosocial Aspects of Child and Family Health, Disaster Preparedness Advisory Council. Supporting the grieving child and family. Pediatrics 2016;138:e20162147. https://pediatrics.aappublications.org/content/138/3/e20162147

\section{Management of mental health issues within primary care practice}

- National Institute of Mental Health. Ask Suicide-Screening Questions (ASO) toolkit. https://www.nimh.nih.gov/research/research-conduct- ed-at-nimh/asq-toolkit-materials/ (free download; available in many languages)

- American Academy of Pediatrics. Mental health tools for paediatrics. Addressing mental health concerns in primary care: a clinician's toolkit. Updated 2019. https://downloads.aap.org/AAP/PDF/Mental_Health_Tools_for_Pediatrics.pdf

- Royal College of General Practitioners. Children and young people's mental health. Mental health toolkit. https://www.rcgp.org.uk/clinicaland-research/resources/toolkits/mental-health-toolkit.aspx

\section{Telepsychiatry}

- Oxford Precision Psychiatry Lab, Oxford Health Biomedical Research Centre. Telepsychiatry and digital technologies in child and adolescent psychiatry. Management of mental health issues within primary care practice. 2020. http://oxfordhealthbrc.nihr.ac.uk/wp-content/uploads/2020/10/5C.-COVID-and-MH_Digital_MH.pdf

\section{Impact of trauma: strategies for self-care and healing}

- National Center on Parent Family and Community Engagement, Early Childhood Learning \& Knowledge Center, US Department of Health and Human Services. Understanding trauma and healing in adults series. 2020. https://eclkc.ohs.acf.hhs.gov/mental-health/article/understanding-trauma-healing-adults

- Early Childhood Learning and Knowledge Center:

- Defining trauma: https://eclkc.ohs.acf.hhs.gov/publication/defining-trauma

- Caring for ourselves as we care for others:

https://eclkc.ohs.acf.hhs.gov/publication/caring-ourselves-wecare-others

- Coping and healing: https://eclkc.ohs.acf.hhs.gov/publication/coping-healing

\section{Children and adolescents with special healthcare needs}

- American Academy of Pediatrics. Caring for children and youth with special health care needs during the covid-19 pandemic. Interim guidance. 2021. https://services.aap.org/en/pages/2019-novelcoronavirus-Covid-19-infections/clinical-guidance/caring-for-childrenand-youth-with-special-health-care-needs-during-the-Covid-19-pandemic/

\section{Schools and covid-19}

- Halladay Goldman J, Danna L, Maze JW, Pickens IB, Ake III GS. National Center for Child Traumatic Stress. Trauma informed school strategies during covid-19. 2020. https://www.nctsn.org/resources/trauma-informed-school-strategies-during-covid-19

- Unesco. Covid-19 education: from disruption to recovery. 2021. https://en.unesco.org/Covid19/educationresponse

\section{Resources for parents, families, caregivers, and children}

\section{General covid-19 resources}

- National Center for School Crisis and Bereavement, Children's Hospital Los Angeles covid-19 pandemic resources. 2020.

https://www.schoolcrisiscenter.org/resources/Covid-19-pandemicresources/

- NHS Lothian, Scotland. Covid-19 resources. https://services.nhslothian.scot/camhs/Resources/Pages/ResourcePacks.aspx\#Parents_and_Carers

- Maudsley Charity, UK. Families Under Pressure. 2020. https://familiesunderpressure.maudsleycharity.org

- American Academy of Pediatrics. Parenting in a pandemic: tips to keep the calm at home. 2020. https://www.healthychildren.org/English/health-issues/conditions/COVID-19/Pages/Parenting-in-aPandemic.aspx 
- Emerging Minds Network: action for child mental health. UK research and innovation. Resources for families and supporters. 2021. https://emergingminds.org.uk/resources-for-families-supporters/

- American Academy of Child and Adolescent Psychiatry. Resources for helping kids and parents cope amidst covid-19. 2020. https://www.aacap.org/AACAP/Families_and_Youth/Resource_Libraries/Covid-19/resources_helping_kids_parents_cope.aspx

- American Academy of Pediatrics. Teens and covid-19: challenges and opportunities during the outbreak. 2020. https://www. healthychildren.org/English/health-issues/conditions/COVID-19/Pages/Teensand-COVID-19.aspx

- Emerging Minds Network: Action for Child Mental Health 2021. UK research and innovation: top tips to support children and young people with their worries and anxiety.https://emergingminds.org.uk/supporting-children-and-young-people-with-worriesand-anxiety-coronavirus/

\section{Children and adolescents with special healthcare needs}

- Family Voices. Coronavirus information and resources. 2021. https://familyvoices.org/Covid19/

- CHILD-BRIGHT Network. Covid-19 resources for Canadian youth with disabilities, their families, and support teams. 2021. https://www.child-bright.ca/covid-19-resources

- Kuo DZ, Coleman C. American Academy of Pediatrics. Covid-19: caring for children and youth with special health care needs. 2021. https://www.healthychildren.org/English/health-issues/conditions/COVID-19/Pages/COVID-19-Youth-with-Special-Health-CareNeeds.aspx

\section{Books and videos for children}

- Free eBooks about covid-19. LibGuide for New York City School Library System. 2021. https://nycdoe.libguides.com/COVID-19ebooks/free (collection of free eBooks in multiple languages for children about coronavirus/covid-19)

- Gomez AM. The Oyster and the Butterfly: The Corona Virus and Me (children's book). 2020. https://www.anagomez.org/wp-content/uploads/dlm_uploads/2020/04/OysterandButterfly-EnglishV3.pdf (free download; translations into 20 additional languages are available here: https://www.anagomez.org/Covid-19-resources/)

- Patuck H, Inter-Agency Standing Committee (IASC) reference group on mental health and psychosocial support in emergency settings, My Hero is You: How Kids Can Fight Covid-19. (children's book). 2020. https://interagencystandingcommittee.org/iasc-reference-groupmental-health-and-psychosocial-support-emergency-settings/myhero-you (free download; translations into many languages are available)

- Johns Hopkins Center for American Indian Health. Our Smallest Warriors, Our Strongest Medicine: Overcoming COVID-19. (children's book). A book written for indigenous American Indian, Alaska Native, First Nations, Métis, and Inuit children. 2020.

https://caih.jhu.edu/programs/strongmedicine (free download)

- Paediatric Society of New Zealand and Starship Foundation. Resources to help explain coronavirus (covid-19) to children. 2020.

https://www.kidshealth.org.nz/resources-help-explain-coronavirusCovid-19-children

Acknowledgments: We thank Lauren Rozenvayn, Yuri Rozenvayn, and another anonymous parent reviewer for their helpful comments on earlier drafts. We also thank four children (ages 6-18) for sharing their experiences and perspectives on the covid-19 pandemic. We are grateful to the BMJ editorial team and reviewers for their helpful comments.

Funding: none

Competing interests: We have read and understood $B M$ J policy on declaration of interests and declare that we have no competing interests.

Contributorship statement: ER conceived the paper, consulted with EA, IS, and PV in developing areas of emphasis, and wrote the first draft. ER, JS, and EA performed literature searches, and all authors contributed additional content and reviewed drafts. ER provided the original tables 1, 2, and 3 and figs 1 and 2, IS provided boxes 1, 3, and 4, and all authors contributed. All authors revised the work for important intellectual content, approve the final submission, and agree to be accountable for all aspects of the work. ER is the guarantor.

Provenance and peer review: commissioned, based on an idea from the corresponding author; externally peer reviewed.

Romeo RD. The impact of stress on the structure of the adolescent brain: Implications for adolescent mental health. Brain Res 2017;1654(Pt B):185-91.

doi: 10.1016/j.brainres.2016.03.021 pmid: 27021951

2 Liu JJ, Bao Y, Huang X, Shi J, Lu L. Mental health considerations for children quarantined because of COVID-19. Lancet Child Adolesc Health 2020;4:347-9. doi: 10.1016/S2352-4642(20)30096-1 pmid: 32224303

3 Schonfeld DJ, Demaria T, Berry S, etalCOMMITTEE ON PSYCHOSOCIAL ASPECTS OF CHILD AND FAMILY HEALTH, DISASTER PREPAREDNESS ADVISORY COUNCIL. Supporting the grieving child and family. Pediatrics 2016;138:20162147. doi: 10.1542/peds.2016-2147 pmid: 27573086

4 Wang G, Zhang Y, Zhao J, Zhang J, Jiang F. Mitigate the effects of home confinement on children during the COVID-19 outbreak. Lancet 2020;395:945-7.

doi: 10.1016/S0140-6736(20)30547-X pmid: 32145186

5 Osofsky JD, Hansel TC, Osofsky HJ, etal. Public health responses and therapeutic interventions. In: Hoven CW. Amsel LV, Tyano S, eds. An International Perspective on Disasters and Children's Mental Health, Integrating Psychiatry and Primary Care. Springer Nature Switzerland AG, 2019: 21-44doi: 10.1007/978-3-030-15872-9_2.

6 Kessler RC, Berglund P, Demler O, Jin R, Merikangas KR, Walters EE. Lifetime prevalence and age-of-onset distributions of DSM-IV disorders in the National Comorbidity Survey Replication. Arch Gen Psychiatry 2005;62:593-602. doi: 10.1001/archpsyc.62.6.593 pmid: 15939837

7 Shonkoff JP, Garner ASCommittee on Psychosocial Aspects of Child and Family HealthCommittee on Early Childhood, Adoption, and Dependent CareSection on Developmental and Behavioral Pediatrics. The lifelong effects of early childhood adversity and toxic stress. Pediatrics 2012;129:e232-46. doi: 10.1542/peds.2011-2663 pmid: 22201156

8 Coller RJ, Webber S. Covid-19 and the wellbeing of children and families. Pediatrics 2020;146:e2020022079. doi: 10.1542/peds.2020-022079 pmid: 32873717

9 Population Division of the Department of Economic and Social Affairs of the United Nations Secretariat. 2019 Revision of World Population Prospects. 2019. https://population.un.org/wpp/

10 Unesco. Covid-19 impact on education. 2020. https://en.unesco.org/covid19/educationresponse 11 World Health Organization. Mental health: strengthening our response. https://www. who.int/news$\mathrm{room} /$ fact-sheets/detail/mental-health-strengthening-our-response

12 American Academy of Pediatrics. Adverse childhood experiences and the lifelong consequences of trauma. Itasca, IL: 2014. https://www.aap.org/en-us/Documents/ttb_aces_consequences.pdf

13 Substance Abuse and Mental Health Services Administration. SAMHSA's concept of trauma and guidance for a trauma-informed approach. HHS Publication No. (SMA) 14-4884. US Dep Heal Hum Serv 2014. https://store.samhsa.gov/system/files/sma14-4884.pdf

14 US Department of Health and Human Services, Administration for Children and Families, Office of Head Start, et al. Brief 1. Defining trauma. 2020. https:/eclkc.ohs.acf.hhs.gov/publication/defining-trauma

15 US Department of Health and Human Services, Administration for Children and Families, Office of Head Start, et al. Brief 2. Caring for ourselves as we care for others. 2020. https:/eclkc.ohs.acf.hhs.gov/publication/caring-ourselves-we-care-others

16 US Department of Health and Human Services, Administration for Children and Families, Office of Head Start, et al. Brief 3. Coping and healing. 2020. https://eclkc.ohs.acf.hhs.gov/publication/coping-healing

17 El-Zoghby SM, Soltan EM, Salama HM. Impact of the covid-19 pandemic on mental health and social support among adult Egyptians. J Community Health 2020;45:689-95. doi: 10.1007/s10900-020-00853-5 pmid: 32468155

18 Mazza C, Ricci E, Biondi S, etal. A nationwide survey of psychological distress among italian people during the covid-19 pandemic: immediate psychological responses and associated factors. Int J Environ Res Public Health 2020;17:3165. do: 10.3390/ijerph17093165 pmid: 32370116

19 Mengin A, Allé MC, Rolling J, etal. Conséquences psychopathologiques du confinement. Encephale 2020;46(3S):S43-52. doi: 10.1016/j.encep.2020.04.007 pmid: 32370983

20 Moccia L, Janiri D, Pepe M, etal. Affective temperament, attachment style, and the psychological impact of the COVID-19 outbreak: an early report on the Italian general population. Brain Behav Immun 2020;87:75-9. doi: 10.1016/j.bbi.2020.04.048 pmid: 32325098

21 Ford T, John A, Gunnell D. Mental health of children and young people during pandemic. BMJ 2021;372:n614. doi: 10.1136/bmj.n614 pmid: 33692087

22 Newlove-Delgado T, McManus S, Sadler K, etalMental Health of Children and Young People group. Child mental health in England before and during the COVID-19 lockdown. Lancet Psychiatry 2021;8:353-4. doi: 10.1016/S2215-0366(20)30570-8 pmid: 33444548

23 Singh S, Roy D, Sinha K, Parveen S, Sharma G, Joshi G. Impact of COVID-19 and lockdown on mental health of children and adolescents: A narrative review with recommendations. Psychiatry Res 2020;293:113429. doi: 10.1016/jpsychres.2020.113429 pmid: 32882598

24 Racine N, Cooke JE, Eirich R, Korczak DJ, McArthur B, Madigan S. Child and adolescent mental illness during COVID-19: A rapid review. Psychiatry Res 2020;292:113307. doi: 10.1016/.jpsychres.2020.113307 pmid: 32707216 
25 Raker EJ, Zacher M, Lowe SR. Lessons from Hurricane Katrina for predicting the indirect health consequences of the COVID-19 pandemic. Proc Natl Acad Sci U S A 2020;117:12595-7. doi: 10.1073/pnas.2006706117 pmid: 32424085

26 Sharma V, Reina Ortiz M, Sharma N. Risk and protective factors for adolescent and young adult mental health within the context of covid-19: a perspective from Nepal. J Adolesc Health 2020;67:135-7. doi: 10.1016/j.jadohealth.2020.04.006 pmid: 32444197

27 Osofsky JD, Osofsky HJ, Weems CF, Hansel TC, King LS. Effects of stress related to the Gulf Oil Spill on child and adolescent mental health. J Pediatr Psychol 2016;41:65-72. doi: 10.1093/jpepsy/jsu085 pmid: 25306404

28 Masten AS, Narayan AJ, Silverman WK, etal. Children in war and disaster. In: Lerner RM, ed. Handbook of Child Psychology and Developmental Science. John Wiley \& Sons, Inc, 2015: 1-42doi: 10.1002/9781118963418.childpsy418.

29 Osofsky JD, Osofsky HJ, Weems CF, King LS, Hansel TC. Trajectories of post-traumatic stress disorder symptoms among youth exposed to both natural and technological disasters. J Child Psychol Psychiatry 2015;56:1347-55. doi: 10.1111/jcpp.12420 pmid: 25898776

30 Wheaton MG, Abramowitz JS, Berman NC, etal. Psychological predictors of anxiety in response to the H1N1 (swine flu) pandemic. Cognit Ther Res 2012;36:210-8doi: 10.1007/s10608-011-9353-3.

31 Vizard T, Sadler K, Ford T, et al. Mental health of children and young people in England, 2020. UK. 2020. https://files.digital.nhs.uk/CB/C41981/mhcyp_2020_rep.pdf

32 Hill RM, Rufino K, Kurian S, Saxena J, Saxena K, Williams L. Suicide ideation and attempts in a pediatric emergency department before and during covid-19. Pediatrics 2021;147:e2020029280. doi: 10.1542/peds.2020-029280 pmid: 33328339

33 Krass P, Dalton E, Doupnik SK, Esposito J. US pediatric emergency department visits for mental health conditions during the covid-19 pandemic. JAMA Netw Open 2021;4:e218533. doi: 10.1001/jamanetworkopen.2021.8533 pmid: 33929525

34 Yard E, Radhakrishnan L, Ballesteros MF, etal. Emergency department visits for suspected suicide attempts among persons aged 12-25 years before and during the covid-19 pandemic-United States, January 2019-May 2021. MMWR Morb Mortal Wkly Rep 2021;70:888-94. doi: 10.15585/mmwr.mm7024e1 pmid: 34138833

35 Marques de Miranda D, da Silva Athanasio B, Sena Oliveira AC, Simoes-E-Silva AC. How is COVID-19 pandemic impacting mental health of children and adolescents? Int J Disaster Risk Reduct 2020;51:101845. doi: 10.1016/j.jjdrr.2020.101845 pmid: 32929399

36 Patrick SW, Henkhaus LE, Zickafoose JS, etal. Well-being of parents and children during the covid-19 pandemic: a national survey. Pediatrics 2020;146:e2020016824. doi: 10.1542/peds.2020-016824 pmid: 32709738

37 Millar R, Quinn N, Cameron J, Colson A. Impacts of lockdown on the mental health and wellbeing of children and young people: Considering evidence within the context of the individual, the family and education. Glasgow: 2020. https:/www.mentalhealth.org.uk/sites/default/files/MHF\%20Scotland\%20Impacts\%20of\%20Lockdown.pdf

38 Davico C, Ghiggia A, Marcotulli D, Ricci F, Amianto F, Vitiello B. Psychological impact of the covid-19 pandemic on adults and their Children in Italy. Front Psychiatry 2021;12:572997. doi: 10.3389/fpsyt.2021.572997 pmid: 33776812

39 Tang S, Xiang M, Cheung T, Xiang YT. Mental health and its correlates among children and adolescents during COVID-19 school closure: The importance of parent-child discussion. J Affect Disord 2021;279:353-60. doi: 10.1016/j.jad.2020.10.016 pmid: 33099049

40 Zhou S-J, Zhang L-G, Wang L-L, etal. Prevalence and socio-demographic correlates of psychological health problems in Chinese adolescents during the outbreak of COVID-19. Eur Child AdolesC Psychiatry 2020;29:749-58. doi: 10.1007/s00787-020-01541-4 pmid: 32363492

41 Duan L, Shao X, Wang Y, etal. An investigation of mental health status of children and adolescents in china during the outbreak of COVID-19. J Affect Disord 2020;275:112-8. doi: 10.1016/j.jad.2020.06.029 pmid: 32658812

42 Garcia de Avila MA, Hamamoto Filho PT, Jacob FLDS, etal. Children's anxiety and factors related to the covid-19 pandemic: an exploratory study using the children's anxiety questionnaire and the numerical rating scale. Int J Environ Res Public Health 2020;17:1-13. doi: 10.3390/ijerph17165757 pmid: 32784898

43 Yeasmin S, Banik R, Hossain S, etal. Impact of COVID-19 pandemic on the mental health of children in Bangladesh: A cross-sectional study. Child Youth Serv Rev 2020;117:105277. doi: 10.1016/j.childyouth.2020.105277 pmid: 32834275

44 Rajkumar RP. COVID-19 and mental health: A review of the existing literature. Asian J Psychiatr 2020;52:102066. doi: 10.1016/j.ajp.2020.102066 pmid: 32302935

45 Gadermann AC, Thomson KC, Richardson CG, etal. Examining the impacts of the COVID-19 pandemic on family mental health in Canada: findings from a national cross-sectional study. BMJ Open 2021;11:e042871. doi: 10.1136/bmjopen-2020-042871 pmid: 33436472

46 Orgilés M, Espada JP, Delvecchio E, etal. Anxiety and depressive symptoms in children and adolescents during covid-19 pandemic: a transcultural approach. Psicothema 2021;33:125-30.pmid: 33453745

47 Widnall E, Winstone L, Mars B, et al. Young people's mental health during the covid-19 pandemic: initial findings from a secondary school survey study in South West England. 2020 https://sphr.nihr.ac.uk/wp-content/uploads/2020/08/Young-Peoples-Mental-Health-during-theCOVID-19-Pandemic-Report-Final.pdf

48 Waite P, Pearcey S, Shum A, etal. How did the mental health symptoms of children and adolescents change over early lockdown during the COVID-19 pandemic in the UK?/CPP Advances 2021;1:1-10doi: 10.1111/jcv2.12009.
49 Cost KT, Crosbie J. Anagnostou E, etal. Mostly worse, occasionally better: impact of COVID-19 pandemic on the mental health of Canadian children and adolescents. Eur Child Adolesc Psychiatry 2021;26:1-14.pmid: 33638005

50 Mansfield K, Jindra C, Fazel M. The OxWell School Survey 2020 report of preliminary findings [not yet published]

51 Penner F, Hernandez Ortiz J, Sharp C. Change in youth mental health during the covid-19 pandemic in a majority Hispanic/Latinx US sample. J Am Acad Child Adolesc Psychiatry 2021;60:513-23. doi: 10.1016/j.jaac.2020.12.027 pmid: 33359408

52 Kardefelt-Winther D. How does the time children spend using digital technology impact their mental well-being, social relationships and physical activity? An evidence-focused literature review. UNICEF Off Res 2017. https://www.unicef-irc.org/publications/925-how-does-the-timechildren-spend-using-digital-technology-impact-their-mental-well.html

53 Thevenon O, Adema W. Combatting covid-19's effect on children. Paris: 2020. https://www.oecd.org/coronavirus/policy-responses/combatting-covid-19-s-effect-on-children2e1f3b2f/

54 Organisation for Economic Co-operation and Development. OECD policy brief. Children \& young people's mental health in the digital age: shaping the future. Paris. 2018. https://www.oecd.org/els/health-systems/Children-and-Young-People-Mental-Health-in-theDigital-Age.pdf

55 Livingstone S, Stoilova M, Nandagiri R. Children's data and privacy online: growing up in a digital age. An evidence review. London: 2019. https://www.lse.ac.uk/media-and-communications/assets/documents/research/projects/childrens-privacy-online/Evidence-review.pdf

56 Europol. Catching the virus: cybercrime, disinformation and the covid-19 pandemic. Europol2020 https://www.europol.europa.eu/publications-documents/catching-virus-cybercrime-disinformationand-covid-19-pandemic

57 Lee J. A neuropsychological exploration of zoom fatigue. Psychiatr Times. https://www.psychiatrictimes.com/view/psychological-exploration-zoom-fatigue

58 Rider EA. Communication with children and families. In: Kline M, Blaney S, Giardino A, etal, eds Rudolph's Pediatrics. 23rd ed. McGraw-Hill, 2018: 6-13.

59 Rider EA. Communication in the pediatric encounter: fostering relationships with children and families. In: Novack D, Daetwyler C, Saizow R, etal, eds. DocCom-an Online Communication Skills Curriculum. Drexel University College of Medicine, 2020

60 Levetown MAmerican Academy of Pediatrics Committee on Bioethics. Communicating with children and families: from everyday interactions to skill in conveying distressing information Pediatrics 2008;121:e1441-60. doi: 10.1542/peds.2008-0565 pmid: 18450887

61 Fegert JM, Vitiello B, Plener PL, Clemens V. Challenges and burden of the Coronavirus 2019 (COVID-19) pandemic for child and adolescent mental health: a narrative review to highlight clinical and research needs in the acute phase and the long return to normality. Child Adolesc Psychiatry Ment Health 2020;14:20. doi: 10.1186/s13034-020-00329-3 pmid: 32419840

62 Dalton L, Rapa E, Stein A. Protecting the psychological health of children through effective communication about COVID-19. Lancet Child Adolesc Health 2020;4:346-7. doi: 10.1016/S2352-4642(20)30097-3 pmid: 32243784

63 Jiao WY, Wang LN, Liu J, etal. Behavioral and emotional disorders in children during the covid-19 epidemic. J Pediatr 2020;221:264-266.e1. doi: 10.1016/j.jpeds.2020.03.013 pmid: 32248989

64 Smirni D. Noli Timere. The role of reassuring adults in dealing with covid-19 anxiety in pediatric age. Pediatr Rep 2021;13:15-30. doi: 10.3390/pediatric13010003 pmid: 33401500

65 Bauer L. The covid-19 crisis has already left too many children hungry in America. Brookings Inst. 2020:1-10. https://www.brookings.edu/blog/up-front/2020/05/06/the-covid-19-crisis-has-already-left-too-many-children-hungry-in-america

66 Nguyen PH, Kachwaha S, Pant A, etal. Impact of COVID-19 on household food insecurity and interlinkages with child feeding practices and coping strategies in Uttar Pradesh, India: a longitudinal community-based study. BMJ Open 2021;11:e048738. doi: 10.1136/bmjopen-2021-048738 pmid: 33883156

67 Center for Translational Neuroscience. A hardship chain reaction: financial difficulties are stressing families' and young children's wellbeing during the pandemic, and it could get a lot worse. Medium. 2020. https://medium.com/rapid-ec-project/a-hardship-chain-reaction-3c3f3577b30

68 Pensiero N, Kelly A, Bokhove C. Learning inequalities during the covid-19 pandemic: how families cope with home-schooling. Southampton: 2020. https://www.southampton.ac.uk/publicpolicy/covid19/learning-inequalities-covid-19.page

69 Gray S, Kellas A. Covid-19 has highlighted the inadequate, and unequal, access to high quality green spaces. BMJ Opinion2020. https://blogs.bmj.com/bmi/2020/07/03/covid-19-has-highlighted-the-inadequate-and-unequal-access-to-high-quality-green-spaces/

70 Millett GA, Jones AT, Benkeser D, etal. Assessing differential impacts of COVID-19 on black communities. Ann Epidemiol 2020;47:37-44. doi: 10.1016/j.annepidem.2020.05.003 pmid: 32419766

71 Bhala N, Curry G, Martineau AR, Agyemang C, Bhopal R. Sharpening the global focus on ethnicity and race in the time of COVID-19. Lancet 2020;395:1673-6. doi: 10.1016/S0140-6736(20)31102-8 pmid: 32401716

72 Fortuna LR, Tolou-Shams M, Robles-Ramamurthy B, Porche MV. Inequity and the disproportionate impact of COVID-19 on communities of color in the United States: The need for a trauma-informed social justice response. Psychol Trauma 2020;12:443-5. doi: 10.1037/tra0000889 pmid: 32478545

73 Kidman R, Margolis R, Smith-Greenaway E, Verdery AM. Estimates and projections of covid-19 and parental death in the US. JAMA Pediatr 2021;175:745-6. doi: 10.1001/jamapediatrics.2021.0161 pmid: 33818598 
74 McFarling UL "They've been following the science": How the covid-19 pandemic has been curtailed in Cherokee Nation. STAT News 2020. https://www.statnews.com/2020/11/17/howcovid19-has-been-curtailed-in-cherokee-nation/

75 Mallard A, Pesantes MA, Zavaleta-Cortijo C, Ward J. An urgent call to collect data related to COVID-19 and Indigenous populations globally. BMJ Glob Health 2021;6:e004655. doi: 10.1136/bmigh-2020-004655 pmid: 33653731

76 Kyoon-Achan G, Write L. Community-based pandemic preparedness: covid-19 procedures of a Manitoba First Nation community. J Commun Safety Well-Being 2020;5:45-50doi: 10.35502/jcswb.131.

77 Whitney DG, Peterson MD. US national and state-level prevalence of mental health disorders and disparities of mental health care use in children. JAMA Pediatr 2019;173:389-91. doi: 10.1001/jamapediatrics.2018.5399 pmid: 30742204

78 Ali MM, West K, Teich JL, Lynch S, Mutter R, Dubenitz J. Utilization of mental health services in educational setting by adolescents in the United States. J Sch Health 2019;89:393-401. doi: 10.1111/josh.12753 pmid: 30883761

79 Loades ME, Chatburn E, Higson-Sweeney N, etal. Rapid systematic review: the impact of social isolation and loneliness on the mental health of children and adolescents in the context of covid-19. J Am Acad Child Adolesc Psychiatry 2020;59:1218-1239.e3. doi: 10.1016/j.jaac.2020.05.009 pmid: 32504808

80 Waite P, Pearcey S, Shum A, et al. How did the mental health of children and adolescents change during early lockdown during the covid-19 pandemic in the UK? PsyArXiv [preprint] 2021. https://psyarxiv.com/t8rfx

81 ECPAT International. Why children are at risk of sexual exploitation during covid-19. 2020. https://ecpat.exposure.co/covid19

82 Schonfeld DJ, Gurwitch RH. Addressing disaster mental health needs of children: practical guidance for pediatric emergency health care providers. Clin Pediatr Emerg Med 2009;10:208-15doi: 10.1016/j.cpem.2009.06.002

83 Wong CA, Ming D, Maslow G, Gifford EJ. Mitigating the impacts of the covid-19 pandemic response on at-risk children. Pediatrics 2020;146:e20200973. doi: 10.1542/peds.2020-0973 pmid: 32317311

84 Saurabh K, Ranjan S. Compliance and psychological impact of quarantine in children and adolescents due to covid-19 pandemic. Indian J Pediatr 2020;87:532-6. doi: 10.1007/s12098-020-03347-3 pmid: 32472347

85 Sprang G, Silman M. Posttraumatic stress disorder in parents and youth after health-related disasters. Disaster Med Public Health Prep 2013;7:105-10. doi: 10.1017/dmp.2013.22 pmid: 24618142

86 Brooks SK, Webster RK, Smith LE, etal. The psychological impact of quarantine and how to reduce it: rapid review of the evidence. Lancet 2020;395:912-20. doi: 10.1016/S0140-6736(20)30460-8 pmid: 32112714

87 Kofman YB, Garfin DR. Home is not always a haven: The domestic violence crisis amid the COVID-19 pandemic. Psychol Trauma 2020;12(S1):S199-201. doi: $10.1037 /$ tra0000866 pmid: 32478558

88 Ragavan MI, Culyba AJ, Muhammad FL, Miller E. Supporting adolescents and young adults exposed to or experiencing violence during the covid-19 pandemic. J Adolesc Health 2020;67:18-20. doi: 10.1016/j.jadohealth.2020.04.011 pmid: 32409152

89 Osofsky JD, Osofsky HJ. Challenges in building child and family resilience after disasters. J Fam Soc Work 2018;21:115-28doi: 10.1080/10522158.2018.1427644.

90 Bothe DA, Olness KN, Reyes C. Overview of children and disasters. J Dev Behav Pediatr 2018;39:652-62. doi: 10.1097/DBP.0000000000000600 pmid: 30059416

91 Sparrow JD. Understanding stress in children. Pediatr Ann 2007;36:187-94. doi: 10.3928/0090-4481-20070401-07 pmid: 17469298

92 Perrin EC, Gerrity PS. There's a demon in your belly: children's understanding of illness. Pediatrics 1981;67:841-9.pmid: 7232049

93 von Soest T, Bakken A, Pedersen W, etalLife satisfaction among adolescents before and during the covid-19 pandemic. Tidsskr Den Nor legeforening 2020;140:30.

94 Zhang Y, Zhang H, Ma X, Di Q. Mental health problems during the covid-19 pandemics and the mitigation effects of exercise: a longitudinal study of college students in China. Int J Environ Res Public Health 2020;17:3722. doi: 10.3390/ijerph17103722 pmid: 32466163

95 Sparrow JD. From developmental to catastrophic: contexts and meanings of childhood stress. Psychiatr Ann 2007;37:397-401doi: 10.3928/00485713-20070601-06.

96 US Department of Health and Human Services, Administration for Children and Families, Office of Head Start, et al. Understanding trauma and healing in adults. 2020. https://eclkc.ohs.acf.hhs.gov/mental-health/article/understanding-trauma-healing-adults

97 American Psychiatric Association. Diagnostic and statistical manual of mental disorders (DSM-5) 5th ed. American Psychiatric Publishing, 2013.

98 Schonfeld DJ, Demaria TDISASTER PREPAREDNESS ADVISORY COUNCIL AND COMMITTEE ON PSYCHOSOCIAL ASPECTS OF CHILD AND FAMILY HEALTH. Providing psychosocial support to children and families in the aftermath of disasters and crises. Pediatrics 2015;136:e1120-30. doi: 10.1542/peds.2015-2861 pmid: 26371193

99 Rider EA. It's because they didn't know our names. Arch Pediatr Adolesc Med 2002;156:531. doi: 10.1001/archpedi.156.6.531 pmid: 12038882
100 Weitzman C. Wegner L, Blum NJ, etalSection on Developmental and Behavioral PediatricsCommittee on Psychosocial Aspects of Child and Family HealthCouncil on Early ChildhoodSociety for Developmental and Behavioral PediatricsAmerican Academy of Pediatrics. Promoting optimal development: screening for behavioral and emotional problems. Pediatrics 2015;135:384-95. doi: 10.1542/peds.2014-3716 pmid: 25624375

101 Swartz J, King HS, Rider EA. Behavioral health screening and referral in the pediatric office. Pediatr Ann 2011;40:610-6. doi: 10.3928/00904481-20111103-07 pmid: 22148276

102 Siu AL, Bibbins-Domingo K, Grossman DC, etalUS Preventive Services Task Force. Screening for depression in children and adolescents: US Preventive Services Task Force recommendation statement. Pediatrics 2016;137:e20154467. doi: 10.1542/peds.2015-4467 pmid: 26908686

103 Horowitz LM, Bridge JA, Teach SJ, etal. Ask Suicide-Screening Questions (ASQ): a brief instrument for the pediatric emergency department. Arch Pediatr Adolesc Med 2012;166:1170-6. doi: 10.1001/archpediatrics.2012.1276 pmid: 23027429

104 National Institute of Mental Health. Ask suicide-screening questions (ASQ) toolkit. 2021.

105 Kemper AR, Hostutler CA, Beck K, Fontanella CA, Bridge JA. Depression and suicide-risk screening results in pediatric primary care. Pediatrics 2021;148:e2021049999. doi: 10.1542/peds.2021-049999 pmid: 34099503

106 Horowitz LM, Mournet AM, Lanzillo E, etal. Screening pediatric medical patients for suicide risk: is depression screening enough?) Adolesc Health 2021;68:1183-8. doi: 10.1016/j.jadohealth.2021.01.028 pmid: 33712380

107 American Academy of Pediatrics. Mental health tools for pediatrics. 2019. https://downloads.aap.org/AAP/PDF/Mental_Health_Tools_for_Pediatrics.pdf

108 Andrews JH, Cho E, Tugendrajch SK, etal. Evidence-based assessment tools for common mental health problems: a practical guide for school settings. Child Schools 2020;42:41-52doi: 10.1093/cs/cdzO24.

109 Zuckerbrot RA, Cheung A, Jensen PS, Stein REK, Laraque DGLAD-PC STEERING GROUP. Guidelines for adolescent depression in primary care (GLAD-PC): Part I. Practice preparation, identification, assessment, and initial management. Pediatrics 2018;141:4081. doi: 10.1542/peds.2017-4081 pmid: 29483200

110 Cheung AH, Zuckerbrot RA, Jensen PS, Laraque D, Stein REKGLAD-PC STEERING GROUP. Guidelines for adolescent depression in primary care (GLAD-PC): Part II. Treatment and ongoing management. Pediatrics 2018;141:4082. doi: 10.1542/peds.2017-4082 pmid: 29483201

111 National Institute for Health and Care Excellence. Depression in children and young people: identification and management. Guidance and guidelines. 2019. https://www.nice.org.uk/guidance/cg28.

112 Herrman H, Stewart DE, Diaz-Granados N, Berger EL, Jackson B, Yuen T. What is resilience? Can J Psychiatry 2011;56:258-65. doi: 10.1177/070674371105600504 pmid: 21586191

113 Center for Pediatric Traumatic Stress. Addressing the psychological and emotional impact of the covid-19 pandemic for children, families, and healthcare staff. Health care tool box. 2021. https://www.healthcaretoolbox.org/tools-and-resources/covid19.html

114 Kazak AE. Pediatric psychosocial preventative health model (PPPHM): research, practice and collaboration in pediatric family systems medicine. Fam Syst Health 2006;24:381-95doi: 10.1037/1091-7527.24.4.381.

115 Kearney CA, Childs J. A multi-tiered systems of support blueprint for re-opening schools following covid-19 shutdown. Child Youth Serv Rev2021;122:105919doi: 10.1016/J.childyouth.2020.105919.

116 Hertz MF, Barrios LC. Adolescent mental health, COVID-19, and the value of school-community partnerships. Inj Prev2021;27:85-6. doi: 10.1136/injuryprev-2020-044050 pmid: 33172840

117 Hillis SD, Unwin HJT, Chen Y, etal. Global minimum estimates of children affected by COVID-19-associated orphanhood and deaths of caregivers: a modelling study. Lancet 2021;673:01253-8.

118 Rider EA. Advanced communication strategies for relationship-centered care. Pediatr Ann 2011;40:447-53. doi: 10.3928/00904481-20110815-08 pmid: 21902122

$119 \mathrm{Kim}$ YJ, Cho JH. Correlation between preventive health behaviors and psycho-social health based on the leisure activities of South Koreans in the covid-19 crisis. Int J Environ Res Public Health 2020;17:1-10.pmid: 32517322

120 American Academy of Pediatrics. Guidance on the necessary use of telehealth during the covid-19 pandemic. Covid-19 interim guidance. 2020. https://services.aap.org/en/pages/2019-novelcoronavirus-covid-19-infections/guidance-on-the-necessary-use-of-telehealth-during-the-covid19-pandemic/

121 Philippine Pediatric Society. Guidelines in the teaching and implementation of basic telemedicine for pediatric trainees. https://pps.org.ph/wp-content/uploads/2021/03/PPS-letter-TelemedicineModule.pdf

122 American Academy of Child and Adolescent Psychiatry. Delivery of child and adolescent psychiatry services through telepsychiatry. 2017. https://www.aacap.org/AACAP/Policy_Statements/2017/Delivery_of_Child_and_Adolescent_Psychiatry_Services_Through_Telepsychiatry.aspx.

123 American Psychiatric Association. Child \& adolescent telepsychiatry. 2021. https://www.psychiatry.org/psychiatrists/practice/telepsychiatry/toolkit/child-adolescent

124 Klein JD, Koletzko B, El-Shabrawi MH, Hadjipanayis A, Thacker N, Bhutta Z. Promoting and supporting children's health and healthcare during COVID-19 - International Paediatric Association Position Statement. Arch Dis Child 2020;105:620-4. doi: 10.1136/archdischild-2020-319370 pmid: 32381517

125 Oxford Precision Psychiatry Lab, Oxford Health Biomedical Research Centre. Telepsychiatry and digital technologies in child and adolescent psychiatry. 2020. http://oxfordhealthbrc.nihr.ac.uk/wpcontent/uploads/2020/10/5C.-COVID-and-MH_Digital_MH.pdf 
126 Ros-DeMarize R, Chung P, Stewart R. Pediatric behavioral telehealth in the age of COVID-19: Brief evidence review and practice considerations. Curr Probl Pediatr Adolesc Health Care 2021;51:100949. doi: 10.1016/j.cppeds.2021.100949 pmid: 33436319

127 Osofsky J, Kronenberg M, Bocknek E, etal. Longitudinal impact of attachment-related risk and exposure to trauma among young children after Hurricane Katrina. Child Youth Care Forum 2015;44:493-510doi: 10.1007/s10566-015-9300-7.

128 Green BL, Grace MC, Vary MG, Kramer TL, Gleser GC, Leonard AC. Children of disaster in the second decade: a 17-year follow-up of Buffalo Creek survivors. I Am Acad Child Adolesc Psychiatry 1994;33:71-9. doi: 10.1097/00004583-199401000-00011 pmid: 8138524 